\title{
Influence of the sex of the transmitting grandparent in congenital myotonic dystrophy
}

\author{
A López de Munain, A M Cobo, J J Poza, D Navarrete, L Martorell, F Palau, \\ J I Emparanza, M Baiget
}

\begin{abstract}
To analyse the influence of the sex of the transmitting grandparents on the occurrence of the congenital form of myotonic dystrophy (CDM), we have studied complete three generation pedigrees of 49 CDM cases, analysing: (1) the sex distribution in the grandparents' generation, and (2) the intergenerational amplification of the CTG repeat, measured in its absolute and relative values, between grandparents and the mothers of CDM patients and between the latter and their CDM children. The mean relative intergenerational increase in the 32 grandparent-mother pairs was significantly greater than in the 56 mother-CDM pairs (Mann-Whitney U test, $p<0.001$ ). The mean expansion of the grandfathers (103 CTG repeats) was also significantly different from that seen in the grandmothers' group (154 CTG repeats) (MannWhitney $U$ test, $p<0.01)$. This excess of non-manifesting males between the CDM grandparents' generation with a smaller CTG length than the grandmothers could suggest that the premutation has to be transmitted by a male to reach the degree of instability responsible for subsequent intergenerational CTG expansions without size constraints characteristic of the CDM range.
\end{abstract}

\section{( $($ Med Genet 1995;32:689-691)}

Myotonic dystrophy (DM) is a multisystem autosomal dominant disorder owing to an unstable CTG repeat sequence in the $3^{\prime}$ untranslated region of a gene coding for a putative protein kinase. ${ }^{1-8}$ The maternal transmission of congenital myotonic dystrophy (CDM) is a striking phenomenon whose cause remains unknown. Clinical studies have shown a close relationship between maternal age of onset and maternal phenotype at the time of pregnancy and the risk of having a CDM child. ${ }^{9}$ Molecular studies have suggested sex related differences in the intergenerational amplification of the DM gene as an explanation for the almost exclusive maternal transmission of CDM. ${ }^{10-12}$ Nevertheless, this explanation does not appear sufficient, and other unknown factors may play an important role. An excess of males in the earliest generations of a clinically ascertained DM pedigree has been observed. ${ }^{13-16}$ To analyse the influence of the sex of the transmitting grandparent in the occurrence of CDM cases, we have studied complete three generation pedigrees of 49 congenital cases (CDM), analysing: (1) the sex distribution in the generation of the grandparents $\left(G_{1}\right)$, and (2) the intergenerational amplification of the CTG repeat (measured in its absolute and relative values) between $G_{1}$ and $G_{2}$ (generation of mothers of CDM cases) and between $G_{2}$ and $G_{3}$ (generation of CDM cases).

\section{Material and methods}

PEDIGREE STUDIES

Forty-nine three generation pedigrees of all CDM cases seen in two Genetic Units in Spain were studied. Clinical information about dead relatives was obtained from medical reports. When no clinical data were available for a given person, analysis of suitable family branches helped us to assess their carrier status. DNA samples from 32 grandparent-mother $\left(G_{1}-G_{2}\right)$ pairs and 56 mother-child $\left(\mathrm{G}_{2}-\mathrm{G}_{3}\right)$ pairs were available for molecular studies.

\section{MOLECULAR STUDIES}

Genomic DNA was isolated from peripheral blood leucocytes by standard procedures. ${ }^{17}$ Southern blots probed with ${ }^{32} \mathrm{P}$ labelled cDNA $25^{4}$ or pGB2. $6^{2}$ and PCR amplified CTG repeat region with DM101 and DM102 primers $^{3}$ were performed to determine the number of CTG repeats.

\section{MEASUREMENT OF THE INTERGENERATIONAL} AMPLIFICATION

The absolute intergenerational variation was defined as: Expansion of the subjectExpansion of the progenitor. A second parameter was introduced to correct the possible bias owing to the (CTG) $)_{n}$ length of the progenitor in the intergenerational variation, since a given absolute intergenerational variation does not have the same significance when the progenitor has a minimal expansion as when he has a greater number of (CTG) $)_{n}$ repeats. Relative intergenerational variation was defined as:

Expansion of the subject-Expansion of the progenitor Expansion of the progenitor

Statistical analyses were performed by means of $\chi^{2}$ or Mann-Whitney $U$ tests when appropriate.

\section{Results}

A total of $76 \mathrm{CDM}$ cases and their 64 mothers were studied. The mother was always the trans- 
Table 1 Absolute intergenerational variations of $C T G_{n}$ repeat

\begin{tabular}{cc}
\hline \multicolumn{2}{c}{ Absolute intergenerational increase (AII) } \\
\hline $\begin{array}{c}\text { G1-G2 } \\
\text { Grandfather-mother } \\
(n=32)\end{array}$ & $\begin{array}{c}\text { G2-G3 } \\
(n=56)\end{array}$ \\
\hline $\begin{array}{c}\text { Mean G1-G2 AII } \\
515 \text { CTGn* }\end{array}$ \\
GF-mother GM-mother $^{*}$ 513** & Mean G2-G3 AII \\
$515^{* *}$ & 899 CTGn* \\
\hline${ }^{*} \mathrm{p}<0.001 .{ }^{* *} \mathrm{p}=0.45$. &
\end{tabular}

Table 2 Relative intergenerational variations of $C T G_{n}$ repeat

\begin{tabular}{|c|c|}
\hline \multicolumn{2}{|c|}{ Relative intergenerational increase (RII) } \\
\hline $\begin{array}{c}\text { G1-G2 } \\
\text { Grandfather-mother } \\
(n=32)\end{array}$ & $\begin{array}{c}G 2-G 3 \\
\text { Mother-congenital DM } \\
(n=56)\end{array}$ \\
\hline$\underset{5 \cdot 66^{*}}{\text { Mean G1-G2 RII }}$ & \\
\hline$\underset{6.03^{* *}}{\text { GF-mother }} \underset{4.03^{* *}}{\text { GM-mother }}$ & $\begin{array}{c}\text { Mean G2-G3 RII } \\
2 \cdot 75^{*}\end{array}$ \\
\hline
\end{tabular}

${ }^{*} \mathrm{p}<0.001{ }^{* *} \mathrm{p}=0.11$.

mitting parent. The sex of the carrier grandparent was known in 49 cases. Forty of 49 grandparents in families with a congenitally affected child were grandfathers and the remaining nine were grandmothers $\left(\chi^{2}\right.$, $\mathrm{p}<0.001)$.

The mean expansion of the 26 grandfathers was 103 CTG repeats with 154 CTG repeats in the six grandmothers (Mann-Whitney $U$ test, $p=0.01$ ).

The mean absolute $G_{2}-G_{3}$ increase was 899 CTG repeats, a significantly greater value than the mean absolute $G_{1}-G_{2}$ amplification, which was 515 CTG repeats (Mann-Whitney U test, p $<0.001)$. However, there were no significant differences between grandfathers and grandmothers (515 v 513 repeats, respectively, Mann-Whitney $U$ test, $p=0.45$ ) (table 1).

The mean relative intergenerational variation in the $G_{1}-G_{2}$ group $(n=32,5.66, S D 4.08)$ was significantly greater than the $\mathrm{G}_{2}-\mathrm{G}_{3}$ group ( $\mathrm{n}=56,2 \cdot 75, \mathrm{SD} 3 \cdot 36$ ) (Mann-Whitney U test, $\mathrm{p}<0.001)$. There were no significant differences between grandfather-mother and grandmother-mother pairs, although the values tended to be higher in the grandfather-mother group (6.03, SD $4 \cdot 24$ for the grandfathers and 4.03 SD 3.07 for the grandmothers, MannWhitney $U$ test, $\mathrm{p}=0 \cdot 11$ ) (table 2).

\section{Discussion}

Several reports have pointed out the influence of the sex of the parental allele on the intergenerational variations of the CTG repeat. At higher CTG lengths maternal transmission results in larger average intergenerational increments. ${ }^{1618}$ On the other hand, several published works have indicated that expansions of repeats at the lower end of the CTG range ( $<100$ CTG repeats) are greater when inherited from males. ${ }^{11121618-21}$

An apparently unexplained excess of male transmitters has been found in the ancestors' generation by several authors. ${ }^{1622-24}$ In our study, despite biased selection of the pedigrees (ascertained according to the presence of a congenital case) we found a similar excess of grandfathers carrying a DM allele. Intergenerational increase of the CTG repeat was greater in the mother-CDM pairs than in the grandparent-mother pairs. Nevertheless, when the absolute increase was corrected to the relative intergenerational increase, there was a greater tendency to an increase when the parental allele was in the premutation range and more clearly when inherited from a male.

According to our data, we can hypothesise that the almost exclusive maternal transmission of CDM cases could be a consequence of several phenomena: first, the low probability for males with a theoretically sufficient CTG length to generate great intergenerational increases characteristic of CDM, owing to the negative selection of DM alleles during spermatogenesis. ${ }^{21}$ Paradoxically, when a child inherits from his father a DM allele with a number of repeats in the CDM range (>1000 repeats), he generally does not have a congenital form. This finding has also been reported recently ${ }^{24}$ in a Brazilian study where a very large expansion of $9 \mathrm{~kb}$ in a non-congenital patient was inherited from a father with cataract as the only sign of DM. As pointed out by the authors, such an expansion inherited from a mother would result in a CDM child. Second, there is decreased reproductive fitness in manifesting DM males because of their phenotype. ${ }^{1}$ Third, the size of the DM allele in the minimally affected grandfathers is smaller than in the DM grandmothers. This fact suggests that the DM allele from the grandfather needs to pass through a daughter in order to reach the CDM repeat range.

The excess of non-manifesting males could also be the result of the absence of females with a CTG length in the 50-60 repeat range. ${ }^{16202223}$ If this is a real phenomenon, it could suggest that the premutation has to be transmitted by a male to reach the degree of instability responsible for subsequent intergenerational expansions without size constraints. The increased stability associated with male transmission could reflect the larger number of cell divisions in spermatogenesis than in oogenesis or that expansion of the CTG repeat is a postzygotic event which would be influenced differentially by maternal or paternal genetic imprinting. ${ }^{23}$

Recently, two cases of paternally inherited CDM have been reported. ${ }^{2526}$ Interestingly, there is also a transmitting grandfather in the family described by Nakagawa et $a l^{25}$ This case shows that, exceptionally, it is possible for the congenital form to be inherited paternally. A possible explanation for this rare event could be based on other unknown factors, perhaps genetically determined and not necessarily linked to the DM locus, which might result in paternal transmission of CDM. Future studies should consider the dynamic behaviour of the CTG repeat in germ cells and in the early stages of the embryo to speculate further on this issue. 
This work was presented at the IV Meeting of The European Neurological Society held in Barcelona, 25-29 June 1994. The study was supported in part by a grant (94/1249) from the Fondo de Investigaciones Sanitarias del Ministerio de Sanidad y Consumo de España.

1 Harper PS. Myotonic dystrophy. Major Series in Neurology vol 21. London: Saunders, 1989

2 Aslanidis C, Jansen G, Amemiya C, et al. Cloning of the essential myotonic dystrophy region and mapping of the putative defect. Nature 1992;355:548-51.

3 Brook JD, McCurrach ME, Harley HG, et al. Molecular basis of myotonic dystrophy: expansion of a trinucleotide (CTG) repeat at the $3^{\prime}$ end of a transcript encoding a protein kinase family member. Cell 1992;68:799-808.

protein kinase family member. Cell 1992;68:799-808.
4 Buxton J, Shelbourne P, Davies J, et al. Detection of an unstable fragment of DNA specific to individuals with unstable fragment of DNA specific to individ
myotonic dystrophy. Nature 1992;355:547-8.

5 Fu YH, Pizzuti A, Fenwick RG Jr, et al. An unstable triplet repeat in a gene related to myotonic muscular dystrophy. Science 1992;255:1256-8.

6 Harley HG, Brook JD, Rundle SA, et al. Expansion of an unstable DNA region and phenotypic variation in myotonic dystrophy. Nature 1992;335:545-6.

7 Mahadevan M, Tsilfidis C, Sabourin L, et al. Myotonic dystrophy mutation: an unstable CTG repeat in the 3 untronstared re

8 Mahadevan M, Amemiya C, Jansen G, et al Structure and genomic sequence of myotonic dystrophy (DM kinase) gene. Hum Mol Genet 1993;2:299-304.

9 Koch MC, Grimm T, Harley HG, Harper PS. Genetic risks for children of women with myotonic dystrophy. Am $\mathcal{J}$ Hum Genet 1991;48:1084-91.

10 Cobo AM, Baiget M, López de Munain A, Poza JJ, Emparanza JI, Johnson K. Sex-related difference in intergenerational expansion of myotonic dystrophy gene Lancet 1993;341:1159-60.

11 Mulley JC, Staples A, Donnelly A, et al. Explanation for exclusive maternal origin for congenital form of myotonic dystrophy. Lancet 1993;341:236-7.

12 Lavedan C, Hofmann-Radvanyi H, Rabes JP, et al. Different sex-dependent constraints in CTG length variation as explanation for congenital myotonic dystrophy. Lancet 1993;341:237

13 Bell J. Dystrophia myotonica and allied diseases. In: The treasury of human inheritance 4. Part V. Cambridge: Cambridge University Press, 1947 .
14 Klein D. La dystrophie myotonique (Steinert) et la myotonie congénitale (Thomsen) en Suisse. $\mathcal{F}$ Genet Hum 1958; 1(suppl 7): 1-328.

15 Brunner HG, Smeets HJM, Nillesen W, et al. Myotonic dystrophy: predictive value of normal results on clinical exploration. Brain 1991;114:2303-11.

16 Harley HG, Rundle SA, Reardon W, et al. Size of the unstable CTG repeat sequence in relation to phenotype and parental transmission in myotonic dystrophy. $A m \mathcal{F}$ Hum Genet 1993;52:1164-74.

17 Miller SA, Dykes DD, Polesky HF. A simple salting out procedure for extracting DNA from human nucleated procedure for extracting DNA from
cells. Nucleic Acids Res 1988;16:1215.

18 Redman JB, Fenwick RG, Pizzutti A, Caskey CT, Relationship between parental trinucleotide CTG repeat length and severity of myotonic dystrophy in offspring. length and severity of my

19 Ashizawa T, Dunne PW, Ward PA, Seltzer WK, Richards CS. Effects of the sex of myotonic dystrophy patients on the unstable triplet repeat in their affected offspring. Neurology 1994;44:120-2.

20 Barceló JM, Mahadevan M, Tsilfidis C, MacKenzie A, Korneluk R. Intergenerational stability of the myotonic dystrophy protomutation. Hum Mol Genet 1993;2:705-9.

21 Jansen G, Willems P, Coerwinkel M, et al. Gonosomal mosaicism in myotonic dystrophy patients: involvement of mitotic events in (CTG) repeat variation and selection against extreme expansion in sperm. Am 7 Hum Genet 1994;54:575-85.

22 Lavedan C, Hofmann-Radvanyi $\mathrm{H}$, Shelbourne $\mathrm{P}$, et al. Myotonic dystrophy: size and sex-dependent dynamics of CTG instability, and somatic mosaicism. Am f Hum Genet 1993;52:875-83.

23 Brunner HG, Brüggenwirth HT, Nillesen W, et al. Influence of the sex of the transmitting parent as well as of parental allele size on the CTG expansion in myotonic dystrophy. Am f Hum Genet 1993;53:1016-23.

24 Passos-Bueno MR, Cerqueira A, Vainzof M, et al. Myotonic dystrophy: genetic, clinical, and molecular analysis of patients from 41 Brazilian families. $\mathcal{F}$ Med Genet 1995;32: $14-18$.

25 Nakagawa M, Yamada H, Higushi I, et al. A case of paternally inherited congenital myotonic dystrophy. 7 Med Genet 1994;31:397-400.

26 Ohya $\mathrm{K}$, Tachi N, Chiba $\mathrm{T}$, et al. Congenital myotonic dystrophy transmitted from an asymptomatic father with a DM specific gene. Neurology 1994;44:1958. 